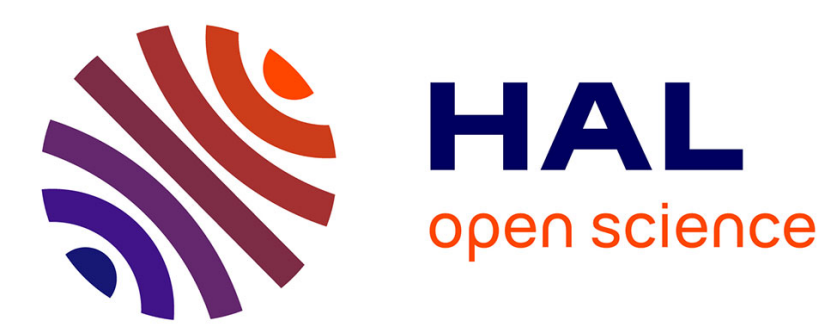

\title{
On the nonlinear deformations of thin unsymmetric 0/90 composite plates under hygrothermal loads
} Marco Gigliotti, Jérôme Molimard, Frédéric Jacquemin, Alain Vautrin

\section{To cite this version:}

Marco Gigliotti, Jérôme Molimard, Frédéric Jacquemin, Alain Vautrin. On the nonlinear deformations of thin unsymmetric 0/90 composite plates under hygrothermal loads. Composites Part A: Applied Science and Manufacturing, 2006, 37 (4), pp.624-629. 10.1016/j.compositesa.2005.05.003 . hal-00292950

\section{HAL Id: hal-00292950 https://hal.science/hal-00292950}

Submitted on 11 Dec 2017

HAL is a multi-disciplinary open access archive for the deposit and dissemination of scientific research documents, whether they are published or not. The documents may come from teaching and research institutions in France or abroad, or from public or private research centers.
L'archive ouverte pluridisciplinaire HAL, est destinée au dépôt et à la diffusion de documents scientifiques de niveau recherche, publiés ou non, émanant des établissements d'enseignement et de recherche français ou étrangers, des laboratoires publics ou privés. 


\title{
On the nonlinear deformations of thin unsymmetric $0 / 90$ composite plates under hygrothermal loads
}

\author{
Marco Gigliottia $^{\mathrm{a}, *}$, Jerome Molimard ${ }^{\mathrm{a}}$, Frédéric Jacquemin ${ }^{\mathrm{b}}$, Alain Vautrin ${ }^{\mathrm{a}}$ \\ ${ }^{a}$ Département Mécanique et Matériaux, Centre SMS, École Nationale Supérieure des Mines de Saint-Étienne, \\ 158 Cours Fauriel, 42023 Saint-Étienne, Cedex 2, France \\ 'Institut de Recherche en Génie Civil et Mécanique, UMR CNRS 6183, Université de Nantes Boulevard de l'Université, \\ BP 406, 44602 Saint-Nazaire Cedex, France
}

\begin{abstract}
The present paper introduces a new method to characterise internal stresses induced by hygrothermal loads on composite laminated plates. The method consists in measuring by the fringe projection technique the full displacement field induced by temperature or moisture absorption on plates with tension-bending coupling, 0/90 unsymmetric plates for instance: internal stresses, whatever the plate typology, can be inferred by such measurements by using a classical theory of plates. When $0 / 90$ plates are very thin, the behaviour can be rather complex, as deformations occur to behave nonlinearly with temperature or absorbed moisture, due to the presence of large displacements. We show the ability of the method to catch experimentally such a nonlinear behaviour and we compare results with a model which takes into account the effect of large displacements.
\end{abstract}

Keywords: Nonlinear deformations; Unsymmetric 0/90 plates; Hygrothermal loads; Fringe projection method

\section{Introduction}

Internal stresses may occur in composite plates due to temperature differentials or moisture absorption. Stress is produced even when the temperature and moisture fields are uniform, due to the intrinsic heterogeneity of composite materials. Such heterogeneity is apparent at two scales: at the microscopic one, due to mismatch between the basic constituents, fibre and matrix, and the mesoscopic one, due to the mismatch of adjacent plies arranged with different fibre orientations with respect to a common direction. It has to be emphasised that internal stresses reside always in composite materials, somehow. When composite parts are produced, they are cooled from the manufacturing temperature to service temperature and this engenders residual internal stress: when in service, polymer composite materials absorb moisture and this is still a source of

\footnotetext{
* Corresponding author. Tel.: +33 477 420076; fax: + 33477420249

E-mail address: vautrin@emse.fr (M. Gigliottia).
}

internal stress. It is sometimes stated that moisture induced stresses counteract residual manufacturing stress. This statement needs to be studied in some detail.

Although much effort has been spent in order to model internal stress, by taking into account complex material behaviour [1], by considering in great detail the actual service life of structural parts put into service [2,3], still a great challenge is to measure such stresses, adequately.

Many techniques have been developed to accomplish this task. At a fine scale, embedded sensors such as optic fibres [4] and strain gages can be used to measure the local internal stress field in heterogeneous structures, provided one is able to interpret correctly the output of such measurements. As far as the macroscopic scale is concerned, the hole drilling method [5], the layer removal method [6] and the compliance method [7] are considered as destructive or semi-destructive methods and are based on the principle of measuring the relaxation of stress induced by performing a hole or a cut or by removing layers from a balanced laminate. These methods are able to provide the stress distribution in a given direction, thus they are able to catch stress gradients or complex stress profiles. Being destructive methods, one could wonder about the possible damage 
development related to the performance of the experiment itself and how such damage could interfere with the actual stress distribution. Unsymmetric laminates are widely used for measuring internal stress indirectly [8-12]. In the presence of internal stress and with no applied mechanical forces these samples bend due to thermo-elastic coupling. Such samples have the merit to provide the stress free state of a sample, as they are practically flat when free of stress: then a plate model has to be used to infer the internal state of stress.

In the present paper attention is paid to this last technique and the fringe projection method is employed to measure the full out of plane displacement field of deformed 0/90 plates. A problem with such plates is that, as they are relatively thin, they can exhibit large displacements under temperature differentials or absorbed moisture, and this in turn may engender a rather complex behaviour, as explained in the second section of the paper.

In this paper we will consider a thermal problem only, the extension to the hygrothermal case does not present special difficulties. We will concentrate our attention on deformations induced by temperature differentials, in a large temperature range.

We will then show the ability of the method to catch experimentally such behaviour and we will show good agreement with a plate model which takes into account the effect of large displacements.

It is important to mention that one of the motivations of the present research is to enhance the quantitative capability of the fringe projection method and the case under study is well adapted to check the powerfulness of the technique. In fact, the fringe projection method is a full-field measurement, which assures no contact with the sample-samples may be in a oven or in an environmental chamber-and introduces no damage on specimens. The method is eventually applicable to full size structures, whatever their shape and the complexity of their displacement field. It is well adapted to reconstruct $2 \mathrm{D}$ or $3 \mathrm{D}$ shapes on computers for additional finite element treatment, it can be used to check tolerances in structural parts.

\section{Behaviour of $0 / 90$ samples under internal stress and model approach}

According to the classical lamination theory (CLT, [13]), which is a linear theory of plates, a 0/90 plate with free edges under thermal stress deform as indicated by the following expression

$w(x, y)=-\frac{1}{2}\left(a x^{2}+b y^{2}\right)$

when referred to a $(x, y, z)$ reference frame. The parameters $a$ and $b$ depend on the material properties of the ply and depend linearly on the temperature differential. When the thickness of the 0 ply and of the 90 ply are equal, $a$ and $b$ have the same magnitude and opposite sign. The deformed shape is exactly a saddle. The parameters $a$ and $b$ are sometimes referred as curvatures: clearly, this is true in the case of small displacements and small strains [14].

It can be experimentally found that for plates in a certain range of dimensions subjected to certain temperature differentials the deformed shape is cylindrical. Actually, two cylinders occur separated by a snap-through phenomenon.

In fact, when the temperature differential is high, out-ofplane displacements are large compared to the thickness of the plate. To explain the phenomenon it is necessary to use geometrical nonlinearities, that is nonlinear relationships between strains and displacements.

The Föppl-Kármán plate theory [14] gives good approximations for highly deformed plates, it takes into account small strains and moderate rotations, but still it is difficult to solve exactly for $0 / 90$ composite plates, due to the presence of coupling.

One alternative solution consists in using a nonlinear approximated method, by employing assumed displacements and an energetic-based procedure. The relevant strains $\varepsilon_{x x}$ and $\varepsilon_{y y}$ depend on the displacement through a nonlinear relationship, as follows:

$\varepsilon_{x x}=\frac{\partial u}{\partial x}+\frac{1}{2}\left(\frac{\partial w}{\partial x}\right)^{2}-z \frac{\partial^{2} w}{\partial x^{2}}$
$\varepsilon_{y y}=\frac{\partial v}{\partial y}+\frac{1}{2}\left(\frac{\partial w}{\partial y}\right)^{2}-z \frac{\partial^{2} w}{\partial y^{2}}$

The assumed displacements depend on some unknown parameter, which is found by solving the following equations

$\delta E=0 ; \quad \delta^{2} E>0$

which states that the first variation of the total potential energy must to be zero for equilibrium configurations. The equilibrium is stable when the second variation is positive definite. $E$ is the total potential energy of the plate, defined as

$E=\int_{V}\left(\frac{1}{2} \vec{\varepsilon} \cdot \underline{Q} \vec{\varepsilon}-\vec{\alpha} T \cdot Q \vec{\varepsilon}\right) \mathrm{d} V$

where $Q$ is the stiffness tensor of a ply, $\vec{\varepsilon}$ is the strain tensor, $\vec{\alpha}$ is the tensor of thermal expansion coefficients, $V$ is the volume of the stressed plate. In the search for the right displacement functions, which have to satisfy kinematics boundary conditions only, one may start, as first suggested by Hyer [15], by assuming the displacements which come from the linear theory, Eq. (1), that is, by employing only two unknown parameters for the out-of-plane displacements.

Fig. 1 shows schematically how a $0 / 90$ plate with inplane dimensions much larger than the thickness behaves when subjected to temperature differential, for example 


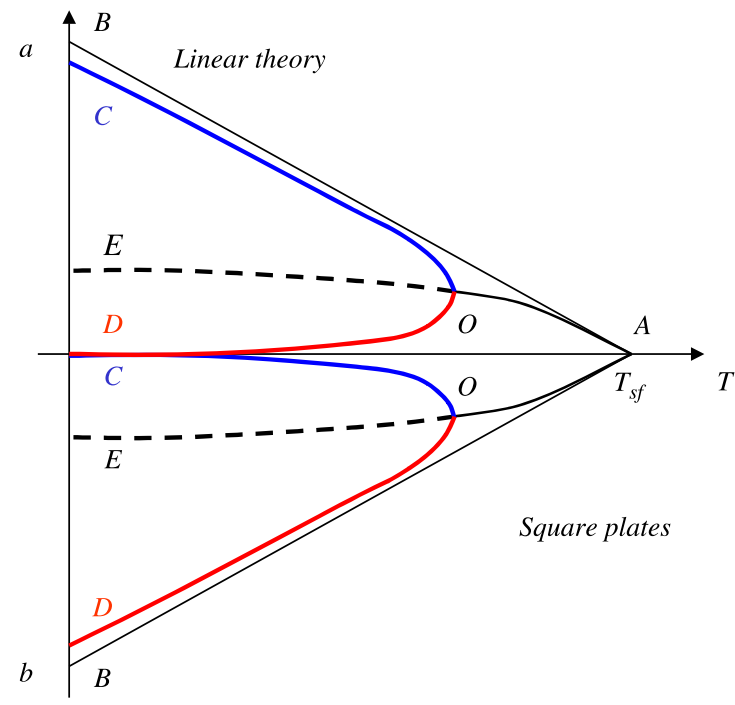

Fig. 1. Schematic behaviour of 0/90 plates under thermal stress.

under cooling from its stress free temperature. Here we consider only square plates, which exhibit a perfect symmetric behaviour. The two parameters $a$ and $b$ are represented as functions of the temperature. They are equal to zero at the stress free temperature, $T_{\text {sf }}$. According to the linear theory the two parameters are of equal magnitude and opposite sign and behave linearly with temperature (path A-B in Fig. 1). The deformed shape is a perfect saddle. When geometrical nonlinearities are taken into account, the two parameters start to exhibit a nonlinear behaviour with temperature, but the deformed shape is still a saddle (path A-O). At a certain temperature (point $\mathrm{O}$ ) the behaviour changes abruptly and the plates start to develop a cylindrical shape, which is progressively more cylindrical as the temperature differential increase (paths $\mathrm{O}-\mathrm{C}, \mathrm{O}-\mathrm{D}$ ). Along path $\mathrm{O}-\mathrm{C}$ the parameter $a$ is different from zero while $b$ tends to zero. The deformed shape is cylindrical, the plate is warped in the $x$-direction. Due to perfect symmetry, an analogous but reverse situation is possible, with $b$ different from zero and $a$ equal to zero (path $\mathrm{O}-\mathrm{D}$ ). In this case the plate is warped in the $y$-direction. Actually the two forms co-exist at a certain temperature separated by a snap-through phenomenon. The saddle shape is not observable, as it is unstable (path $\mathrm{O}-\mathrm{E}$ ). This phenomenon, at least as predicted by the approximated numerical method, is analogous to the buckling of rods or plates. The model has been recently discussed in [16] through a comparison with finite element methods. FEM are based exactly on the same principles and procedures discussed above but they employ more elements and more parameters, thus they can provide a better understanding of the phenomenon. In [16] almost perfect agreement was found for square plates and quite poor agreement was found for rectangular plates: for plates with high Aspect Ratio (length-to-width ratio), the behaviour turned out to be linear on a wide range of temperatures, this phenomenon was ascribed to a beam-like behaviour of plates with high Aspect Ratio, see the cited reference for further details.

It is evident that, in order to understand the true behaviour of such plates, whatever the range of dimensions, we need experimental support. The problem is not easy as we do not need simply to measure a curvature or a deflection, but we need to check the relevance of a field approximation, Eq. (1) for instance.

The steps for such accomplishment will be detailed in the next section, relatively to square plates only.

\section{Fringe projection method for the displacement field measurement}

A traditional experimental technique, which is widely used for 0/90 specimens [8-11], consists of measuring the cord length, the height and the thickness of the samples and then, by assuming that the deformed shape is an arc of circle, calculating the curvature, $k$, which is the inverse of the radius of the circle 0 , see Fig. 2. This experimental technique assumes a given deformed shape.

It exists moreover an intrinsic discrepancy between the model and the traditional experimental technique: in the model the assumed shape is parabolic, while the traditional experimental method measure a circle's arc. For a circle, the curvature is constant at every point, by definition. For a parabolic shape, as mentioned, the second derivative is constant but it approximates the curvatures only for small displacements and small strains.

We propose a fringe projection method for the measurement of the out-of-plane displacements. This method is in principle very well adapted for the measurement of the out-of-plane displacements and suitable to characterise the deformed shapes.

It has to be mentioned that, besides fringe projection, other optical experimental methods for reconstructing and measuring deformed shapes are available: among others, we should recall stereo-correlation, deflectometry, holographic interferometry,... ([17]).

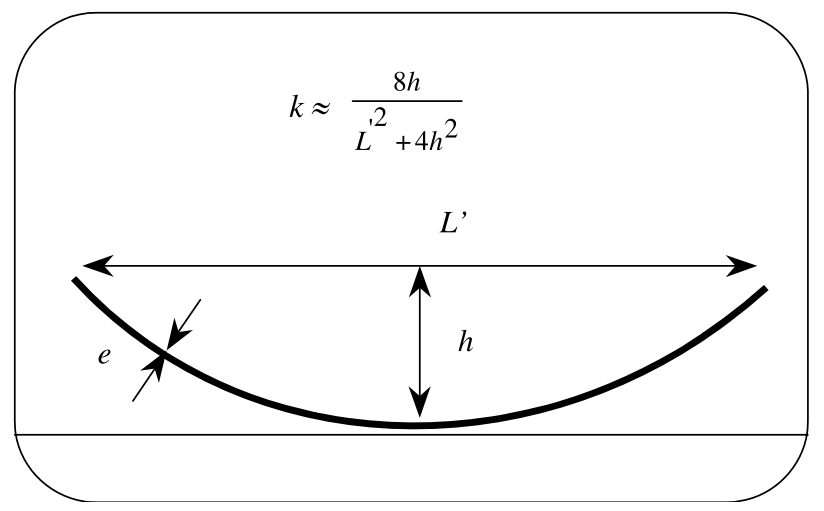

Fig. 2. Traditional experimental technique (Refs. [8-11]). 


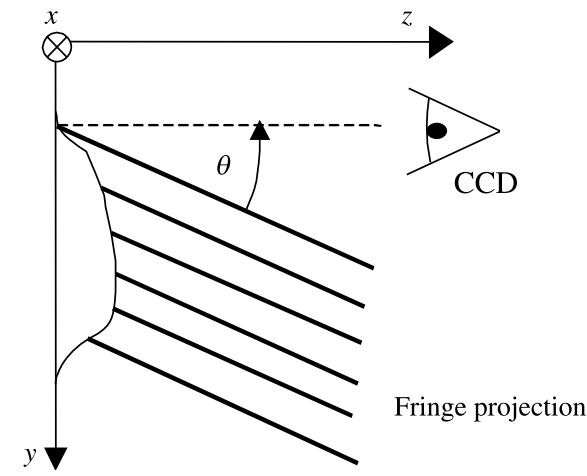

Fig. 3. Schematic of the fringe projection method.

The principle of the method is very simple. Some fringes, a periodic pattern of white and black lines, are projected on an object, reflected by it and captured by a CCD videocamera, see Fig. 3. As long as the object is absent the light intensity can be described mathematically by a periodic function:

$I_{l i}(x, y)=I_{0}\left[1+\gamma \cos \left(\frac{2 \pi}{p} y\right)\right]$

characterised by an average intensity $I_{0}$, a pitch, $p$, which is the distance between two light peaks, and a contrast, $\gamma$.

When the object is present, the fringes are shifted. This is mathematically described by a phase shifting $\varphi$ at each point of the field $(\varphi=\varphi(x, y))$

$I_{\mathrm{obj}}(x, y)=I_{0}\left[1+\gamma \cos \left(\frac{2 \pi}{p} y+\varphi(x, y)\right)\right]$

The computer code Frangyne [18] performs the phase extraction, through inverse Fourier transform. Details of such procedure are not given here.

Once the phase is obtained, the out-of-plane displacements $w(x, y)$ can be calculated according to the following equation:

$\varphi(x, y)=2 \pi \frac{\tan \theta}{p} w(x, y)$

The given equation is obtained by assuming that the rays of light are parallel to each other, thus the angle $\theta$ between the camera and the video projector is assumed constant over the whole spatial field, see Fig. 3. The electronic devices, such as the camera or the video projector, are not modelled, their contribution is neglected. The relationship between phase and out of plane displacements (Eq. (7)) is characterised by the sensitivity $S$ :

$S=2 \pi \frac{\tan \theta}{p}$

This parameter can be adjusted by modifying the pitch $p$ or the angle $\theta$ between the CCD camera and the videoprojector. The minimum displacement which can be captured by such a technique is somehow limited by the noise introduced by the electronic devices and the phase extraction procedure. In the present test a value of $1 / 10 \mathrm{~mm}$ for the minimum measurable displacement was realised. Obviously, expression (7) can be improved by taking into account many other parameters [19].

\section{Results and discussion}

A $\left[0_{2} / 90_{2}\right]$ unsymmetric plate (average dimensions: $120 \mathrm{~mm} \times 120 \mathrm{~mm} \times 0.6 \mathrm{~mm}$ ) made of THR180/EH84 carbon/epoxy composite material was produced at a cure temperature $T_{\text {cure }}=120{ }^{\circ} \mathrm{C}$ in one $90 \mathrm{~min}$ temperature dwell. The temperature ramp to reach cure temperature was about $3{ }^{\circ} \mathrm{C} / \mathrm{min}$. After cure, the sample (Fig. 4a) was placed in a oven where the temperature was raised from $T_{\text {room }}$ to $T_{\text {cure }}$ and the evolution of its shape was monitored through the optical apparatus in Fig. 4b. (a)

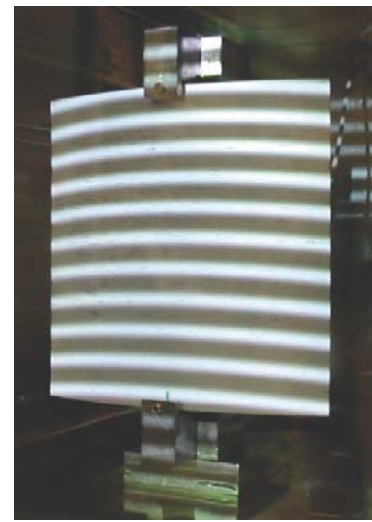

(b)

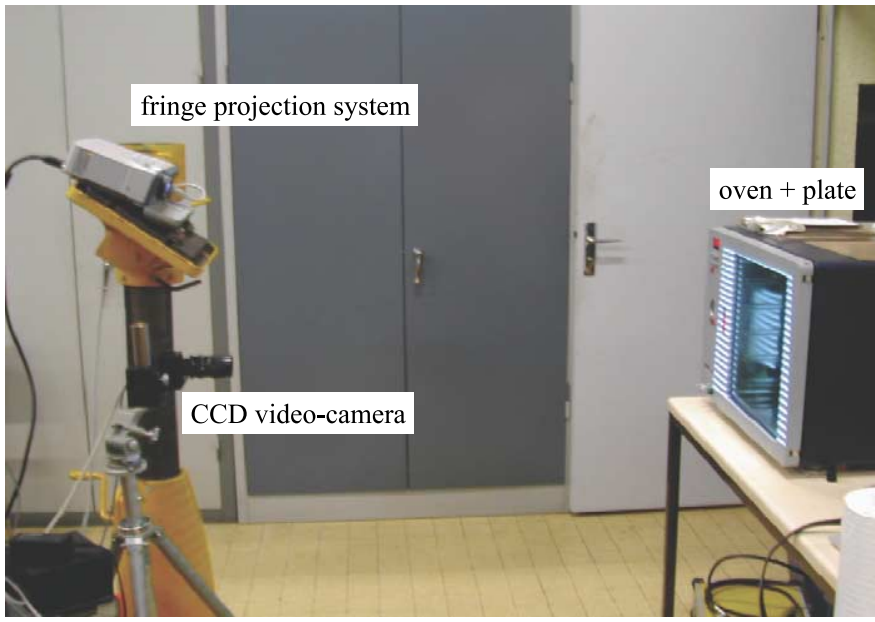

Fig. 4. The plate and its support (a), the optical apparatus (b). 

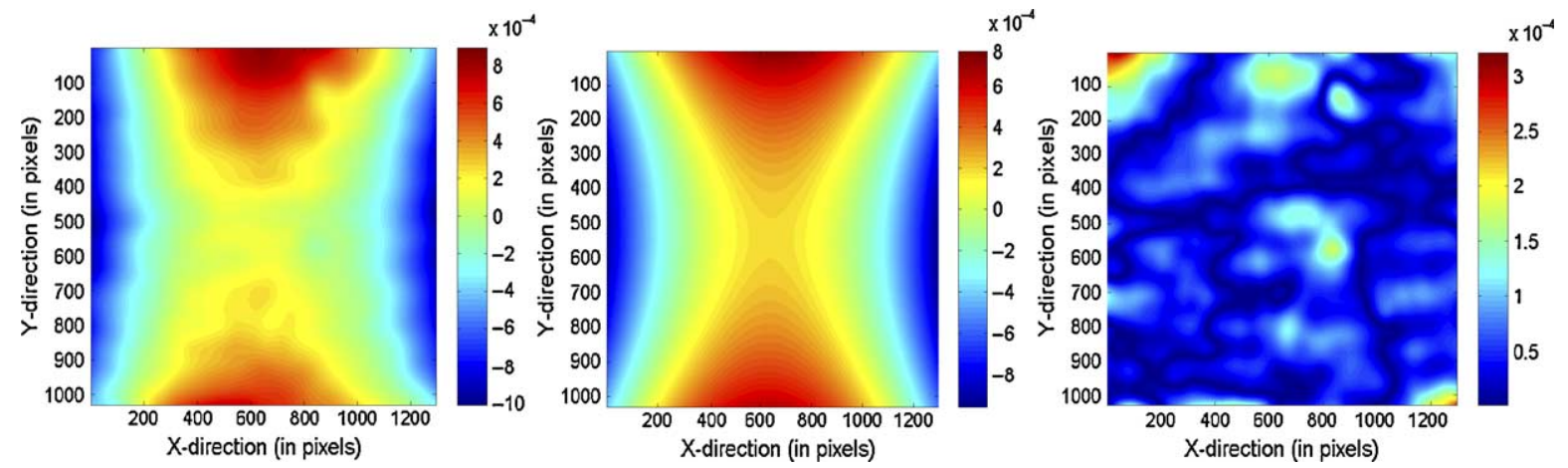

Fig. 5. Experimental shape, parabolic numerical approximation and absolute error for $0 / 90$ plates subject to $\Delta \mathrm{T} \approx-5{ }^{\circ} \mathrm{C}$ (with respect to $T_{\mathrm{sf}}$ ).
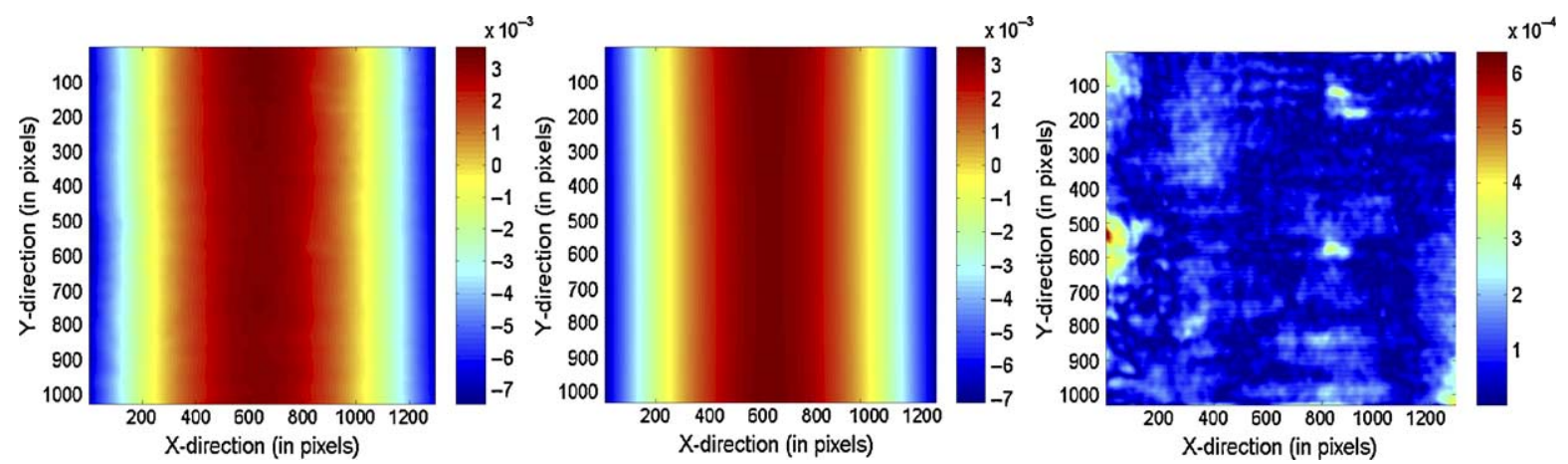

Fig. 6. Experimental shape, parabolic numerical approximation and absolute error for $0 / 90$ plates subject to $\Delta T \approx-90{ }^{\circ} \mathrm{C}$ (with respect to $T_{\text {sf }}$ ).

The temperature on the plate was measured by a temperature gauge situated very close to the sample; also, the plate was painted on one side to allow the light to be sufficiently reflected.

The measured $T_{\mathrm{sf}}$ was found to be around $T_{\text {cure }}$ (see also Fig. 7).
Experimental results show that when the plate is subjected to a small temperature differential $\left(\Delta T \approx-5^{\circ} \mathrm{C}\right.$, starting from $T_{\mathrm{sf}}$ ), the deformed shape is a saddle (Fig. 5).

Fig. 5 shows on the left the experimental shape, at the centre the numerical approximation obtained by fitting all the experimental points and on the right the absolute error

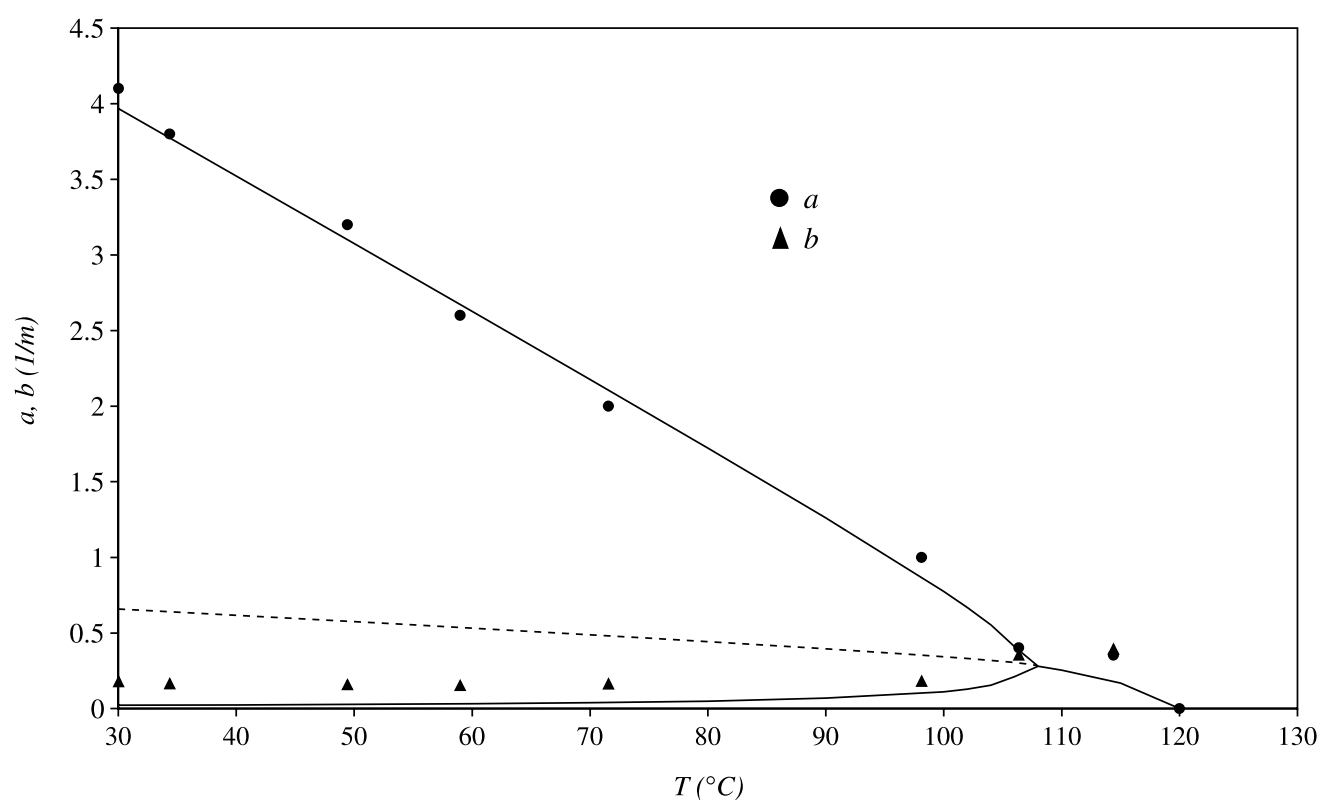

Fig. 7. Comparison between numerical and experimental curvatures. 
Table 1

Material properties used in the simulations

\begin{tabular}{lllll}
\hline$E_{1}(\mathrm{GPa})$ & $E_{2}(\mathrm{GPa})$ & $G_{12}(\mathrm{GPa})$ & $\alpha_{1}\left(\varepsilon^{\circ} \mathrm{C}^{-1}\right)$ & $\alpha_{2}\left(\varepsilon^{\circ} \mathrm{C}^{-1}\right)$ \\
\hline 152 & 8.5 & 4.5 & $0.09 \times 10^{-6}$ & $37 \times 10^{-6}$
\end{tabular}

between the two. The error is very small on the whole field, except few zones, the deformed shape is a saddle with very good approximation. When the temperature differential is higher $\left(\Delta T \approx-90{ }^{\circ} \mathrm{C}\right.$, starting from $\left.T_{\mathrm{sf}}\right)$ the deformed shape is cylindrical (Fig. 6). The quantitative information is gained by fitting the experimental points with a polynomial function by a least-square method and by extracting the parameters of such polynomial approximation.

Fig. 7 show the evolution with temperature of the parameters $a$ and $b$, as extracted by fitting the experimental points. A numerical simulation, the continuous lines, is shown together with the experimental points. The $a$ and $b$ curvatures are actually of opposite sign but are reported in only one picture for clarity. Material properties for numerical simulations are summarised in Table 1, subscript 1 refers to the fibre direction while subscript 2 indicates the direction transverse to fibres.

The temperature at which the solution bifurcates seems to be well captured by the experiments, the transition saddle-cylinder is confirmed, even though is not much clear whether the transition is so abrupt as predicted by the theory. From a quantitative point of view some discrepancies are visible, but the trend is very good.

It should be mentioned that, by using the measured parameters and a classical lamination plate model, the residual stresses in a general laminate can be estimated.

For instance, it suffices to know the measured $T_{s f}$ to evaluate the temperature gap to room temperature that can be used as an input to calculate the thermal stresses in a laminated plate by the CLT.

In the present case the ply residual stresses at room temperature in a [0/90]s plate amount to around $30 \mathrm{MPa}$.

\section{Conclusions}

The accuracy in the prediction of the nonlinear deformations of $0 / 90$ plates under thermal stress has been checked by a novel experimental technique, the fringe projection method.

This technique has great advantages with respect to other experimental techniques; it is contact-less, thus well adapted to the problem under study and introduces no damage on the samples. A very important point is that no a-priori assumptions are made on the true full displacement field of the deformed plate.

A good qualitative and quantitative agreement is found between predictions from the model and experimental measured shapes; the transition from saddle-like to cylindrical shape, predicted at some temperature during the heat-up/cooldown ramp, is confirmed.

This result contributes to the problem of measuring internal stresses in composite laminates and to the quantitative improvement of a technique that has many technical and scientific applications.

\section{References}

[1] White SR, Kim YK. Process-induced residual stress analysis of AS4/3501-6 composite material. Mech Compos Mater Struct 1998;5: 153-86.

[2] Jacquemin F, Vautrin A. A closed-form solution for the internal stresses in thick composite cylinders induced by cyclical environmental conditions. Compos Struct 2002;58:1-9.

[3] Gigliotti M, Jacquemin F, Vautrin A. Internal stresses in composite laminates due to cyclical hygrothermal loading. application to supersonic flight, AIAA J Submitted.

[4] Vacher S, Molimard J, Gagnaire H, Vautrin A. Embedded fibre optic sensors for real time RFI process monitoring in structural health monitoring 2002. In: Balageas DL, editor. Proceedings of the first European workshop, ENS Cachan, 2002. p. 1126-33.

[5] Sicot O, Gong XL, Cherouat A, Lu J. Determination of residual stress in composite laminates using the incremental hole-drilling method. J Compos Mater 2003;27:831-44.

[6] Ersoy N, Vardar O. Measurement of residual stresses in layered composites by compliance method. J Compos Mater 2000;34:575-98.

[7] Manson JE, Seferis JC. Process simulated laminate (PSL): a methodology to internal stress characterisation in advanced composite materials 1992;26:405-31.

[8] Kim KS, Hahn HT. Residual stress development during processing of graphite/epoxy composites. Compos Sci Technol 1989;36:121-31.

[9] White SR, Hahn HT. Process modelling of composite materials: residual stress development during cure. Part II: experimental validation. J Compos Mater 1992;26:2423-53.

[10] Sarrazin H, Kim B, Ahn SH, Springer GS. Effects of processing temperature and lay-up on springback. J Compos Mater 1995;10: 1278-94.

[11] Tarsha-Kurdi KE, Olivier P. Thermoviscoelastic analysis of residual curing stresses and the influence of the autoclave pressure on these stresses in carbon-epoxy laminates. Compos Sci Technol 2002;62: 559-65.

[12] Gigliotti M, Wisnom MR, Potter KD. Development of curvature during the cure of AS4/8552 [0/90] unsymmetric composite plates. Compos Sci Technol 2003;63:187-97.

[13] Herakovitch C. Mechanics of fibrous composites. NewYork: Wiley; 1997.

[14] Timoshenko S, Woinowsky-Krieger S. Theory of plates and shells. NewYork: McGraw Hill; 1954.

[15] Hyer MW. Calculation of the room-temperature shapes of unsymmetric laminates. J Compos Mater 1981;15:296-310.

[16] Gigliotti M, Wisnom MR, Potter KD. Loss of bifurcation and multiple shapes of thin [0/90] unsymmetric composite plates subject to thermal stress. Compos Sci Technol 2004;64:109-28.

[17] Williams DC, editor. Optical methods in engineering metrology. London: Chapman and Hall; 1993.

[18] Surrel Y. Phase stepping: a new self-calibrating algorithm. Appl Optics 1993;32:3598-600.

[19] Breque C, Dupre JC, Bremand F. Calibration of a system of projection-moiré for relief measuring: biomechanical applications. Optics Lasers Eng 2004;41:241-60. 